\title{
Erector spinae plane block for open nephrectomy: a new paediatric success
}

\author{
Nogueira G. ${ }^{1}$, Artilheiro V. ${ }^{2}$, Costa G. ${ }^{3}$, Ferreira J.L.. ${ }^{3}$ \\ 1 Hospital Vila Franca de Xira, Anaesthesiology Department, Lisboa, Portugal \\ ${ }^{2}$ Centro Hospitalar de Lisboa Ocidental, Anaesthesiology Department, Lisboa, Portugal \\ ${ }^{3}$ Centro Hospitalar Universitário de Lisboa Central, Anaesthesiology Department, Lisboa, Portugal
}

\section{Background}

Open nephrectomy is associated with severe pain and pain-derived morbidity. There are several options for postoperative pain management, each one with its own drawbacks. Since its description in $2016^{1}$, erector spinae plane block (ESPB) has been deemed as a safe and effective regional technique.

We present one of the few reports of a paediatric open nephrectomy, managed with the novel ESPB.

\section{Clinical case}

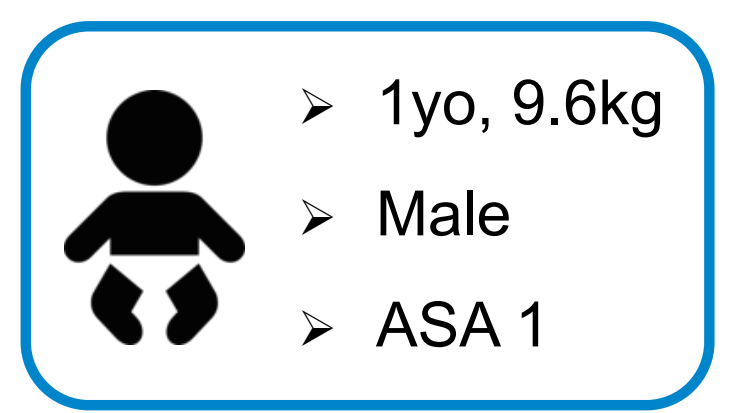

\section{Preoperative}

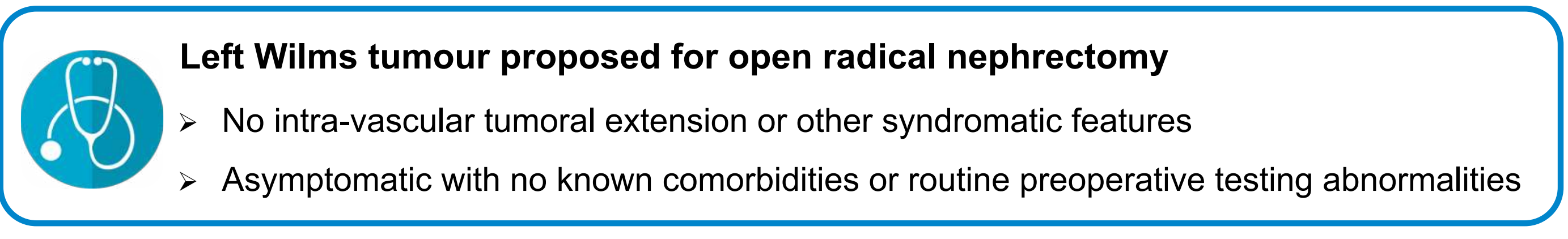

\section{Intraoperative}

Inhaled induction with sevoflurane

Tracheal intubation after IV induction

General

Anaesthesia

$\checkmark$ Fentanyl $2 \mathrm{mcg} / \mathrm{kg}$

$\checkmark$ Propofol $3 \mathrm{mg} / \mathrm{kg}$

$\checkmark$ Rocuronium $0.6 \mathrm{mg} / \mathrm{kg}$

\section{Opioid-sparing anaesthesia}

$\checkmark$ Fentanyl bolus of $1 \mathrm{mcg} / \mathrm{kg}$ prior to incision (partially installed block)

\section{Multimodal analgesia}

$\checkmark$ Acetaminophen $7.5 \mathrm{mg} / \mathrm{kg}$

$\checkmark$ Metamizole $20 \mathrm{mg} / \mathrm{kg}$

$\checkmark$ Regional analgesia

Regional

Anaesthesia

Surgery

\section{Positioning}

$\checkmark$ Left lateral decubitus

\section{US scanning}

$\checkmark$ Longitudinally

$\checkmark$ Parasagittal to T7-T9

Technique

$\checkmark$ In-plane needle insertion

- Craniocaudal orientation

- T8 left transverse process (TP) identification

Bolus of $0.5 \mathrm{~mL} / \mathrm{kg}$ Ropivacaine $0.2 \%$
- Injection deep to Erector Spinae Muscle (ESM)

- Craniocaudal LA spread from T6 to T10

\section{Postoperative}

\section{Recovery from anaesthesia in PACU \\ $\checkmark$ Uneventful}

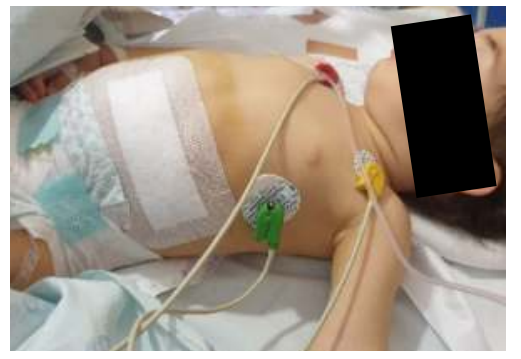

Follow-up on Surgical ward

$\checkmark$ FLACC score of 2 the first $24 \mathrm{~h}$ and of 1 until discharge

$\checkmark$ No need of rescue analgesia

\section{Discussion}

Multimodal analgesia poses as the best approach to open nephrectomy pain, particularly by avoiding opioids and NSAIDs. ESPB, a recently described block, is effective in providing somatic and visceral analgesia by craniocaudal LA spread. ${ }^{2}$ Its clinical applications are still not thoroughly established and are currently expanding. Therefore, our report supports ESPB as a valid pain management alternative for open nephrectomy in children.

\section{References}

[1] Forero M, et al. Reg Anesth Pain Med. 2016;41:621-627. 